\title{
Depictives: An LFG Approach
}

\author{
Yasir Hameed Alotaibi ${ }^{1}$ \\ ${ }^{1}$ The Department of Arabic Linguistics, Prince Sattam bin Abdulaziz University, Al Kharj, Saudi Arabia \\ Correspondence: Yasir Hameed Alotaibi, Prince Sattam bin Abdulaziz University, Al Kharj, Saudi Arabia. E-mail: \\ y.alotaibi@psau.edu.sa
}

$\begin{array}{lc}\text { Received: February 10, } 2019 & \text { Accepted: March 7, } 2019 \text { Online Published: April 20, } 2019 \\ \text { doi:10.5539/ijel.v9n3p188 } & \text { URL: https://doi.org/10.5539/ijel.v9n3p188 }\end{array}$

\begin{abstract}
The main aim of this paper is to discuss two issues in analyzing depictive constructions. The first issue is related to Modern Standard Arabic (MSA), where there is an overlap between depictives and adverbs. This paper distinguishes between depictives in MSA, where the word in accusative case is adjective and adverbs, where the word in accusative case is a verbal noun. The second issue that is discussed in this paper is the syntactic analysis of depictives. In this regard, we contribute a new analysis within the Lexical Functional Grammar (LFG) framework, in which depictives are analyzed as single adjuncts that modify participants in the main predicate in the same way as adjectives, when they function as modifiers, do.
\end{abstract}

Keywords: depictive, small clause, adjunct, Lexical Functional Grammar

\section{Introduction}

Depictive constructions are defined in the literature as a structure that modifies a participant in the main predicate throughout the duration of the event in the main predicate (see Schultze-Berndt \& Himmelmann, 2004; Bruening, 2018). However, in some languages, depictive constructions are overlap with close constructions, such as adverbs, where a modifier characterizes an event in the main predicate, rather than a participant. The main reason behind this confusion between the two constructions is that a modifier in depictive constructions modifies a participant that is involved in the event and the adverb in adverbial constructions modifies an event that has some participants. In both constructions, the challenge is to outline the border between events and participants. This problem in Modern Standard Arabic (MSA) is worse than other languages, because MSA exhibits two types of adverbs and the difference between both is in morphology level. The first type of adverbs contains a preposition preceding a verbal noun, as shown in (1a), while the second type is a verbal noun carrying an accusative case marking, as shown in (1b). The second type is mixed with depictives in traditional grammar and other analyses, because depictives in MSA carry the same case marking and this added a new complication to the fact that a depictive in somehow may characterizes the event with a participant in this event, in which the participant is its main target.

(1) a. ğāia sālim-un bi-ğạab-in. come.PFV.3SGM Salem-NOM with-anger.VN-GEN

'Salem came angrily'

b. harağa zayd-un bagtat-an.

leave.PFV.3SGM Zayd-NOM suddenly.VN-ACC

'Zayd left suddenly'

In addition to this semantic issue in analyzing depictive constructions, there is another problem in the syntax. The main syntactic analyses in the literature analyze depictives within the generative grammar frameworks. In such analyses, depictives are analyzed as small clauses by Chomsky (1981), Stowell (1982) and Hoekstra (1988) or as simple adjuncts by Williams (1980) and Winkler (2011). Both analyses had to deal with two issues in analyzing depictives. The first one is the relationship between the main predicate and the depictive and the second issue is the relationship between the controller and the depictive. This paper will discuss the two issues and provides a new analysis of depictives, using the Lexical Functional Grammar (LFG) framework. Additionally, the location of depicticves in the constituent structure (c-structure) is an important issue in 
generative syntax frameworks, but it is less important in LFG, which has two levels of presentations: c-structure and functional structure (f-structure). The second structure should deal with the two relationships in depictive constructions and therefore this paper will focus on $\mathrm{f}$-structure in syntactic analysis of depictives.

Section 2 in this paper displays dpictives in MSA. It shows the type of words that can be used in this structure, the case marking that should be carried by depictives and the functions of controllers. Section 3 gives general explanation of the difference between depictives and adverbs and then uses them for distinguishing depictives from adverbs in MSA. Section 4 provides a syntactic analysis of depictives within the LFG framework.

\section{Data}

This section is devoted to the date of depictives in MSA and describes some important characteristics of this phenomenon in MSA. It is divided into two subsections: the first describes depictive constructions in MSA and shows the type of words that can function as depictives in MSA and the case marking of depictives. The second subsection is devoted to the controller in depictive constructions, showing the relationship between the controller and the depictive in MSA. Also, it shows that the controller in MSA is different in that it has no specific syntactic functions or thematic roles.

\subsection{Depictives}

The depictive construction in MSA was discussed in traditional grammar and called alhāl. Alhāl was defined in Ryding (2005) as a word in accusative case that represents the circumstances under which an action occurs. Depictives are illustrated in the following examples and they are written in italic font, carrying an accusative case marking:

(2) a. ğầa sālim-un $\dot{g} \bar{a} d i b-a n$. come.PFV.3SGM Salem-NOM angry.APTCP.SGM-ACC

'Salem came angry'

b. harağa zayd-un bākī-an.

leave.PFV.3SGM Zayd-NOM crying.APTCP.SGM-ACC

'Zayd left crying'

The two examples above show that depictives in MSA are always accusative. The active participle gādib-an 'angry' in example (2a) and bāki-an crying' in (2b) carry an accusative case marking. Both are active participles and this type of words usually function as adjectives in MSA (see Ryding, 2005) and using participles as adjectives is not only in MSA, but it is possible in other languages, such as European Languages, as shown by Berger (2005). Thus, we can state that the class of word that can be used as depictives in MSA is adjective that is derived from verbs, meaning that depictives in MSA should be deverbal. Some traditional grammarians argue that all types of deverbal can be used as depictives including verbal nouns (see Alaqili (nd)). A verbal noun that is analyzed as a depictive in this analysis is shown in the following example:

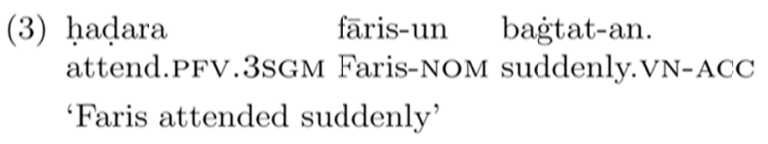

Bagtat-an 'suddenly' in example (3) is a verbal noun that cannot function as an adjective in MSA. This word is similar to depictives in that it carries an accusative case marking and functions as a modifier, but in this paper we will argue against analyzing such examples as depictives in MSA. We will argue that bagtat-an 'suddenly' in example (3) functions as an adverb and adverbs are different from depictives in spite of that they are analyzed as one category in traditional grammar and in Ryding (2005) as well. Ryding (2005) classified alhāl as a type of adverbs. The term in Ryding (2005) may mean adjunct, but it causes an overlap between depictives and adverbs. The difference between adverbs and depictives in MSA will be discussed later in section 3 .

In addition, there is an important difference between depictives, which were shown in (2), and a verbal noun such as the one in example (3), supporting analyzing it as an adverb. This difference is that depictives in (2a) and (2b) agree in gender and number with their controller. In (2a), the controller of the depictive gädib-an 'angry' is Salem and both are masculine and singular. The same agreement occurs between the depictive and the controller in example (2b). If we change the controller to feminine, as shown in (4a), or plural as shown in (4b), the 
examples will be ungrammatical with the same depictive.

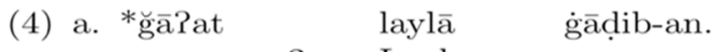
come.PFV.3SGF Layla.NOM angry.APTCP.SGM-ACC

'Layla came angry'

b. *harağa al-țullāb-u bākī-an.
leave.PFV.3SGM DEF-student.PL-NOM crying.APTCP.SGM-ACC
'the students left crying'

In contrast, changing the expected controller to feminine as shown in (5a), or plural as shown in (5b) is possible with the same verbal noun in (3).

(5) a. haḍarat laylā bag̀tat-an.

attend.PFV.3SGF Layla.NOM suddenly.VN-ACC

'Layla attended suddenly'

b. hạạara al-țullāb-u bağtat-an.

attend.PFV.3SGM student.PL-NOM suddenly.VN-ACC

'The students attended suddenly'

These examples show that there is a difference between adjectives in accusative case and verbal nouns in accusative case in MSA. Based on that, we will argue that depictives or alhāl in MSA should be adjectives. Other structures, such as the one in (3), will be analyzed as adverbs, as will be shown in details in section 3 .

Adjectives and adjectival phrases are usually the main category that functions as depictives in MSA and in other languages. A number of authors, such as Van der Auwera and Malchukov (2005), Müller-Bardey (2005), McGregor (2005), Berger (2005), Simpson (2005) and others, who discuss depictives in a variety types of languages restrict their discussion of depictives to adjectives. In this paper, we argue that a word in accusative case that functions as a real depictive should be an adjective. However, depictive function in MSA can be fulfilled by a clause headed by a verb or a nominal sentence preceded by a conjunction. The same example of depictive in (6a) can be paraphrased as (6b) or (6c) and all the three examples deliver the same semantic content.

(6) a. ğāia sālim-un dāḥik-an.

come.PFV.3SGM Salem-NOM laughing.APTCP.SGM-ACC

'Salem came laughing'

b. ğāia sālim-un yaḍhaku.

come.PFV.3SGm Salem-NOM laugh.IPFV.3SGM

'Salem came laughing'

c. ğāia sālim-un wa huwa ḍaḥik-un.

come.PFV.3SGM Salem-NOM and he laughing.APTCP.SGM-NOM

'Salem came laughing'

In example (6a), an active participle, which is an adjective, is a single word functioning as a depictive and it carries an accusative case marking. The function of depictive in $(6 b)$ is done by a verb in the imperfective form and the subject of the main clause Salem controls the subject of this verb in the imperfective form. In the last example in (6c), the function of depicive is done by a nominal sentence, which is a verbless sentence in MSA. The subject or topic in this sentence is the pronoun huwa 'he' that takes the subject of the main verb as its antecedent and the predicate is the active participle dāhik-un 'laughing'. This paper will focus on adjectives that function as depictives in examples such as (6a). However, this kind of depictive in MSA may require an object that has no controller in the main clause. When an adjective is derived from a transitive verb, it usually requires an object carrying an accusative case marking. The following examples illustrate: 


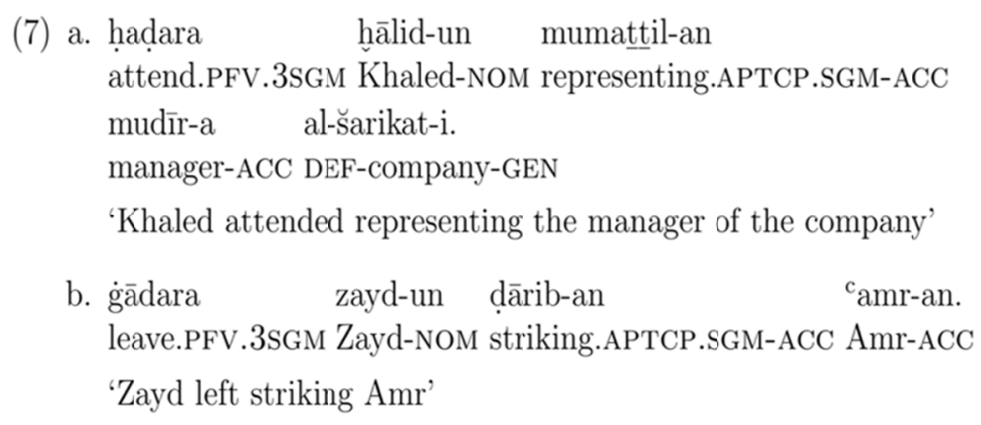

In example (7a), the depictive is mumattil-an 'representing', which is an active participle, and it requires an object function that is filled by the noun mudir-a 'manager', which carries an accusative case marking. The same issue is in example (7b), the active participle darib-an 'striking' is the depictive and it requires an accusative object, which is the proper noun $A m r$.

\subsection{Controller}

The depictive is analyzed as a second predicate in many accounts of this phenomenon and the second predicate is usually related to the main predicate by a controller in the main predicate. The controller should control the subject of a depictive if we assume that it is a second predicate. In some languages, including English, there are syntactic and semantic restrictions on the controller in depictive constructions. In English, depictives are controlled by the subject of the main clause if the verb in the main clause is intransitive, or by the subject or the object if the verb in the main clause is transitive. Also, there are restrictions on the thematic roles of the controller in depictive constructions in the English language, restricting controllers to specific thematic roles, such as agent, patient and theme (For discussing these syntactic and semantic restrictions in English, see Williams, 1980; McNulty, 1988; Müller, 2002; Bayer, 2013). However, languages are not the same in imposing these restrictions on the function of controllers and they differ in which participants are accessible as controllers (see Nichols, 1978; Müller-Bardey, 1989).

Laughren (1992), Müller (2000) and Schultze-Berndt and Himmelmann (2004) argue that grammatical functions, such as subject or object, should be avoided when we discuss controllers, because languages are different in using controllers filling syntactic functions. Also, in some languages, controllers may be covert, meaning that they do not overtly fill any grammatical function in the main predicate. Therefore, they conclude that the relation between depictives and the main predicate is not a syntactic relation, but it is a semantic relation. This means that controllers in depictive constructions are semantic participants. In this paper, we suggest that MSA has a special status regarding syntactic functions and thematic roles of controllers. In MSA, the controller has no specific syntactic functions, meaning that depictives can be controlled by any function in the main predicate. Thus, the controller can be a subject, an object, an object of a preposition, or an adjunct. All these functions can be controllers in MSA. Similarly, any thematic role in the main predicate can be controlling depictives in MSA. The following examples show different types of controllers in MSA, in which the controller is written in bold font and the depictive written in italic font:

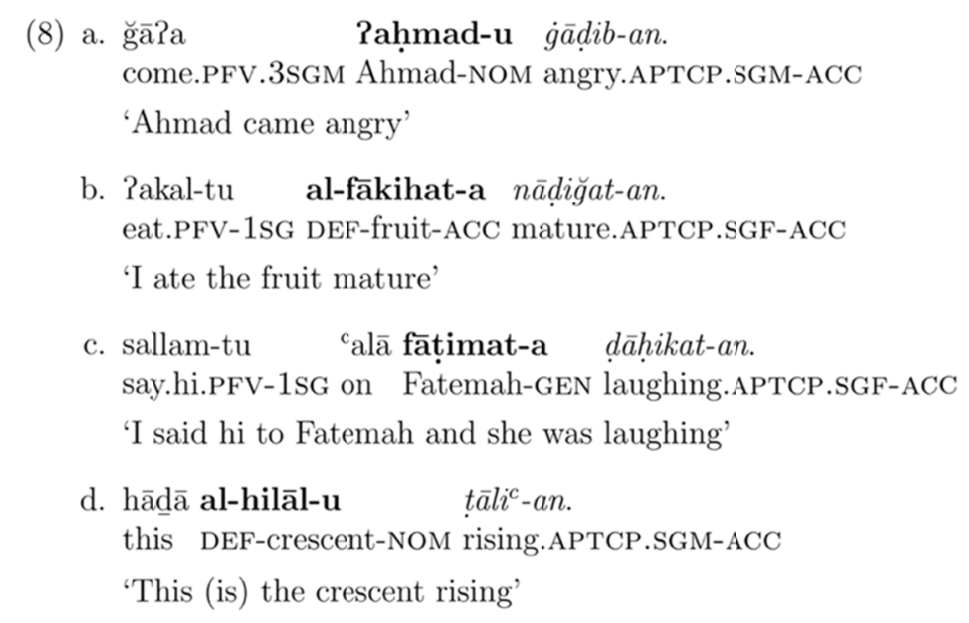




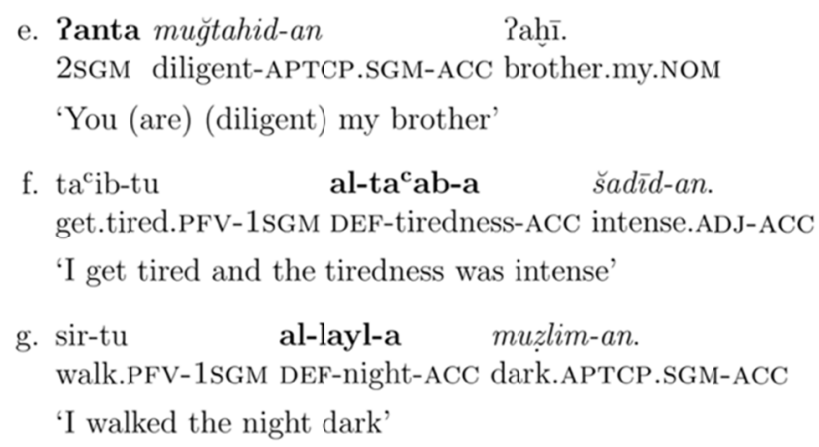

In example (8a), the controller is the subject of the main predicate Ahmad, while in (8b), the controller is the object of the main predicate al-fäkihat-a 'the fruit' and in (8c), the controller is the proper noun Fatemah, which is preceded by the preposition ${ }^{c}$ ala 'on'. Example (8d) and (8e) contain verbless sentences which begin with a topic and are completed by a comment. In the former, the controller is the comment al-hilāl-u 'the crescent', while the controller in the latter is the topic ?anta 'you'. Finally, the controllers in (8f) and $(8 \mathrm{~g})$ function as an adjunct. The verbal noun $a l-t a^{c} a b-a$ 'the tiredness' in (8f) is the controller and the temporal adverb al-layl-a 'the night' is the controller in (8g). This means that MSA does not impose any restrictions on the syntactic functions of controllers and controllers of depictives can be any syntactic function. Also, the thematic roles of controllers differ in MSA and can be agent, patient, experiencer, recipient, or other thematic roles.

Additionally, all syntactic functions or thematic roles are the same in the degree of accessibility as controllers, meaning that no syntactic functions or thematic roles take priority over others in being a controller. Therefore, a sentence can be ambiguous if it has two possible controllers, as shown below. This example contains two arguments functioning as a subject and object (both are written in bold font) and both are possible controllers for the depictive (written in italic font). There is no priority for the subject or its thematic role to be a controller. In this case, the context should specify the right controller.

(9) daraba zayd-un camr-an bāke-an.

hit.PFV.3SGM Zayd-NOM Amr-ACC crying.APTCP.SGM-ACC

'Zayd hits Amr (crying)'

Importantly, as mentioned before, the agreement between controllers and depictives in gender and number is obligatory. However, there is no agreement between them in person. The following examples show the agreement between controllers and depictives (the controllers are written in bold and the depictives written in italic).

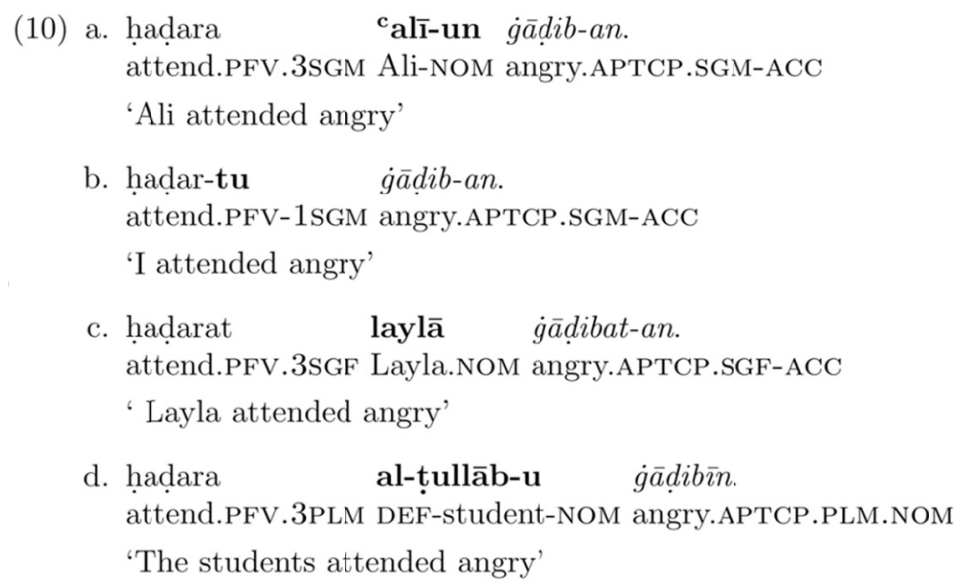

Example (10a) has a third person, masculine and singular controller and in example (10b), the controller differs in that it is in first person. Because depictives do not agree in person with the controller, the same depictive modifies both controllers. In (10c), the controller is feminine and in (10d), the controller is plural, and the two depictives agree with both controllers in gender and number. 


\section{Depictives vs. Adverbs}

This section discusses the similarities and differences between depictive and adverbial constructions. It focuses on semantic meaning of both constructions. It starts with general similarities and differences between both constructions and then tries to relate them to MSA, which is the topic of this paper. The main characteristic of depictives is that they modify a participant in the main predicate, while the main characteristic of adverbs is that they modify the event of the main predicate, but there is a shared area between both constructions, because adverbs may modify a participant in some constructions and the following lines explain this issue. This section is divided into two subsections: the first explains general differences and similarities between depictives and adverbs, while the second discusses these differences and similarities in MSA.

\subsection{Depictives and Adverbs in General}

The main characteristic of depictives is that they are participant-oriented, modifying a participant in the main predicate. In other words, depictives express a state that holds during the reference time of the main predicate for a participant in the main clause. The following examples illustrate depictives in the English language (the depictives are written in italic font and their controllers in bold font):

(11) a. John bought the chicken fresh .

\section{b. Sue left angry.}

In example (11a), the depictive is fresh and the controller is the chicken. Importantly, this depictive is participant-oriented, modifying the object of the main predicate the chicken. Example (11b) is different in that the participant that is modified by the depictive is the subject of the main predicate Sue. If we compare this semantic meaning of depictives with a typical adverb modifying an event in the main predicate (event-oriented), such as the one in example (12a) below, we find that the adverb angrily, which has a different morphological form, modifies the event left, rather than the participant Mary. In this example, the anger is in the way of leaving, rather than the person who left. In the same way, the adverb stupidly modifies the event spoke and this means that the adverb ascribes the stupidity to the way Mary spoke, rather than Mary.

(12) a. Mary left angrily.

b. Mary spoke stupidly.

However, there is an overlap between depictives and adverbs in syntactic and semantic levels in many languages. In the semantic level, adverbs are not only event-oriented and can show orientation towards a participant in the main predicate (see Jackendoff, 1972; Platt \& Platt, 1972; Bartsch, 1976, McConnell-Ginet, 1982; Dik \& Hengeveld, 1991; Ernst, 2000). This fact makes an overlap between depictives and adverbs in semantic meaning. Geuder (2002) and Himmelmann and Schultze-Berndt (2006) discuss some of this kind of adverbs, which exhibit participant-orientation. In English, the position of the adverb can help in specifying the semantic meaning that is conveyed by it. For example, the same adverbs that are shown in (12) can give different meanings if they are placed in different positions. The following examples, which are taken from Geuder (2002, pp. 29-34), show the adverbs angrily and stupidly preceding main verbs and conveying different meanings. In both examples, the adverbs give something about the manner of performing the action, but they do not convey the manner in the same way as the examples in (12) do. The two examples in (13) add statements about participants in the main predicates. In (13a), the anger is not only in the manner of breaking the door and the subject he is angry while he is breaking the door. The adverb in (13b) is called agentive by Geuder (2002), because it ascribes a characteristic to the agent John on the basis of answering the question. As mentioned by Himmelmann and Schultze-Berndt (2006, p. 8), this example can be paraphrased as 'it was stupid of John to answer the question' and this paraphrase clearly indicates that the adverb modifies both the subject and the verb. This means that both adverbs in both examples are event-oriented and participant-oriented at the same time.

(13) a. 'He angrily broke the door open'.

b. 'John stupidly answered the question'.

We conclude that orientation towards a participant in the main predicate is a feature that is shared by depictives and adverbs. However, there is a semantic difference between the two constructions, namely, depictive constructions differ from adverbial constructions in that they do not show any evaluation of the event in the main predicate. For example, the depictive fresh in example (11a) or angry in (11b) do not describe the events bought and left in both sentences. In other words, they should be only interpreted with one of the participants in the main clause. In contrast, adverbs should be event-oriented, meaning that they should convey some description about the manner in which the event occurs. For example, angrily in example (12a) and stupidly in (12b) do not convey 
anything towards the participants in both examples. They only modify the events left and spoke. However, as stated above, adverbial constructions can exhibit a participant orientation, but they should be with event-orientation. In other words, they should describe a participant on the basis of the event that is performed by the participant. Examples of these adverbs are shown in examples (13a) and (13b) above. In languages like English, as shown in the previous examples, there is an important morphological difference between depictives, which are usually in adjectival forms and adverbs, which are usually ended by $l y$. This difference may reduce the overlap between the two phenomena. However, the case in MSA is different in relation to morphology, as will be shown in the remainder of this section.

\subsection{Depictives and Adverbs in MSA}

MSA is the same as other languages in the semantic difference between depictive and adverbial constructions. This means that depictives in MSA are participant-oriented and adverbs are event-oriented. However, there are two types of adverbs in MSA and the difference between them is in the morphological form. They can be prepositional phrases or verbal nouns in accusative case.

Adverbial constructions in MSA can be prepositional phrases that contain a preposition preceding a verbal noun. The following examples show prepositional phrases functioning as adverbs in MSA:

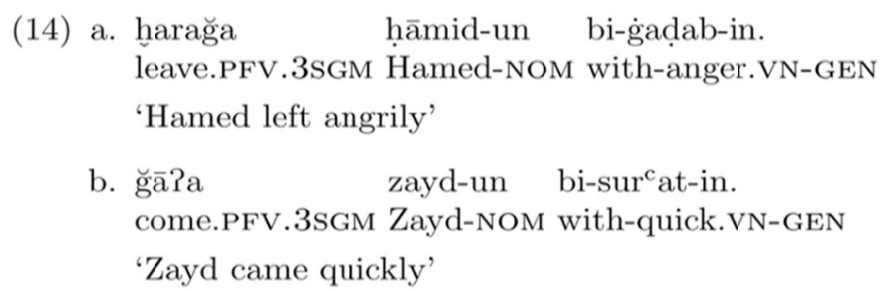

In both examples above, the prepositional phrases function as adverbs. In semantic level, they show the manner of performing the event in both sentences. In example (14a), the prepositional phrase bi-gadab-in 'angrily' shows the manner of leaving. In this example, Hamed left in angry way and this does not mean that he is angry (he may pretend that he is angry). It is possible that Hamed is angry, but the prepositional phrase does not ensure that and this interpretation may be understood from the manner of leaving, because if you leave in angry manner, you should be angry. Similarly, the prepositional phrase bi-sur $^{c}$ at-in 'quickly' in example (14b) modifies the verb $g \bar{a}$ ?a 'came' and shows how it is performed. The main evidence that supports our interpretation in both examples is that the verbal nouns in both examples do not agree with any participant in the main predicate. For example, gadab 'anger' in example (14a) does not agree in gender or number with the proper noun Hamed and the second example is the same. This means that the prepositional phrases in both examples are different from depictives in MSA, which agree with the controller in gender and number and therefore, they are participant-oriented. This point will be used in distinguishing between two types of alhāl in MSA below.

As shown above, alhāl is a term that was used in traditional grammar to cover all nouns that carry an accusative case marking and show the circumstances under which the action occurs and in Ryding (2005), alhāl is analyzed as a type of adverbs. In this paper, we argue that there are two types of alhāl: the first one is participant-oriented and we will assume that it is a depictive and the second is event-oriented and we will assume that it is an adverb. As shown above, what is called alhāl can be in an adjective form or in a verbal noun form. The following repeated examples show both:

$$
\begin{aligned}
& \text { a. ğāia sālim-un gạạ̣ib-an. } \\
& \text { come.PFV.3SGM Salem-NOM angry.APTCP.SGM-ACC } \\
& \text { 'Salem came angry' } \\
& \text { b. hadara fāris-un baġtat-an. } \\
& \text { attend.PFv.3SGM Faris-NOM suddenly.VN-ACC } \\
& \text { 'Faris attended suddenly' }
\end{aligned}
$$

Example (15a) contains the active participle gādib-an 'angry', which is used as an adjective in MSA. We argue that this word is functioning as a depictive, because it is a participant-oriented and this interpretation is based on that the depictive agrees with the controller Salem in gender and number. We assume that the agreement shows that there is a relationship between the depictive and the participant in the main predicate. In contrast, the word bagtat-an 'suddenly' in accusative case in example (15b) is not a depictive, because it is not a participant-oriented and this can be inferred from the fact that this verbal noun does not agree with any 
participant in the main predicate in gender and number as depictives do. Instead, we argue that the semantic function of this verbal noun is to modify the event and therefore it is event-oriented. Thus, this paper argues that alhāl in MSA is two types: the first is a depictive and the second is an adverb. It is a depictive if it is a participant-oriented and this happens when it is in an adjective form agreeing with a participant in the main predicate. Otherwise, it is an adverb and in this case, it is a verbal noun that does not agree with any participant in the main predicate, but it modifies the verb, meaning that it is event-oriented.

However, what we analyze as depictives in this paper may show orientation towards the event in main predicate depending on their semantic meaning. For example, a depictive such as nahim 'insatiable' with a verb, such as Pakala 'ate', as shown in the following example, does some kind of modification to wards the manner of performing the event. In this case, this paper assumes that the main function of this adjective is to modify the participant and the orientation of the event is understood from the semantic meaning of the adjective. Therefore, we assume that this adjective is a depictive and a participant-oriented. Also, the same overlap can be with verbal nouns, which are assumed to be adverbial constructions, meaning that some verbal nouns that function as adverbs can show orientation towards a participant based on their semantic meaning.

(16) Pakala fāris-un nahim-an.

eat.PFV.3SGM Faris-NOM insatiable.ADJ.SGM-ACC

'Faris ate insatiable'

\section{Analysis}

This section discusses the syntactic analysis of depictive constructions. It opens by a brief introduction about the LFG framework, which is used for the analysis in this paper. Then, this section discusses the syntactic analysis of depictive constructions. It shows two possible analyses for this phenomenon in generative syntax, where depictives are analyzed as small clauses or single adjuncts. In this paper, we argue for analyzing depictives as single adjuncts, but with some differences in the analysis. In generative syntax, another difficulty comes from the debate about the structural position of depictives in the tree, whether depictives are immediate constituents of the clause or they are constituents of the VP (see Williams, 1980; Andrews, 1983; Rothstein, 1983; Himmelmann \& Schultze-Berndt, 2005). This paper will not discuss this problem, because it uses the LFG framework, where the c-structure is less important in analyzing depictives. Therefore, we will focus on the f-structure in LFG, which should represent the syntactic function of depictives.

\subsection{An Overview of $L F G$}

In this section, we should give a brief overview of LFG, which is the framework that will be used in analyzing depictive constructions. The Lexical Functional Grammar theory is lexical, because the lexicon is central in analyzing many phenomena that are analyzed in the syntax in other frameworks. It is functional because the grammatical functions are very important in the formalism of LFG and they are shown in a separate structure named functional structure (f-structure). LFG is the same as other theories in that words form constituents which are shown in a tree and licensed by rules and in making use of the principle of $\mathrm{x}$-bar theory (for more information about x-bar theory, see Jackendoff, 1977; Chomsky, 1986; Dalrymple, 2001). LFG has the advantage of containing two levels of presentation. Beside the constituent structure in LFG, there is another structure in this framework representing syntactic function called f-structure and the syntactic discussion in this paper will focus on this structure. The f-structure in LFG shows a function from ATTRIBUTES to their VALUES. The following f-structure (quoted from Dalrymple, 2001, p. 30) illustrates:

$$
\left[\begin{array}{ll}
\text { ATtribute } 1 & \text { VAlue } 1 \\
\text { ATtribute } 2 & \text { VAlue } 2
\end{array}\right]
$$

Governable grammatical functions, such as SUBJ, OBJ, COMP, XCOMP.etc, modifiers, such as ADJ or XADJ, or morphosyntactic features, such as NUM or TENSE can be attributes in an f-structure. The values of these attributes are atomic elements, such as FUTURE for the attribute TENSE. Also, the value may be a semantic form that is presented in single quotes showing that this value is unique, such as 'John'. The following f-structure in (18b) represents the sentence in (18a): 
(18) a. John saw Mary.

b. $\left[\begin{array}{lll}\text { PRED } & \text { 'see }<(\text { SUBJ, OBJ })>' \\ \text { TENSE } & \text { past } \\ \text { SUBJ } & {\left[\begin{array}{ll}\text { PRED } & \text { 'JOHN'} \\ \text { NUM } & \text { SG }\end{array}\right]} \\ \text { OBJ } & {\left[\begin{array}{ll}\text { PRED } & \text { 'MARY' } \\ \text { NUM } & \text { SG }\end{array}\right]}\end{array}\right]$

The first attribute in the f-structure above is PRED and its value is a semantic form containing the argument list, which shows the arguments that are required by the verb saw. The verb in this example requires two arguments: SUBJ and OBJ. The second attribute in this f-structure is TENSE and its value is PAST, which is the tense of this sentence. The following attributes are SUBJ and OBJ and their values are embedded f-structures showing information about the subject and object in this example.

\subsection{The Analysis of Depictives}

The syntactic analysis of depictives should represent two relationships in this construction. The first relationship holds between the main predicate and the depictive. The second relationship is between the depictive and the controller, which is usually used to support analyzing depictives as predicates. In general, there are two main analyses that are proposed for depictives in generative grammar. The first analysis treats depictives as small clauses. In other words, a depictive is analyzed as a subordinate clause functioning as an adjunct and this subordinate clause has an empty category PRO functioning as the subject of this clause. The PRO in this case is controlled by the subject of the main clause in the construction. This proposal has been supported by Chomsky (1981), Stowell (1982) and Hoekstra (1988).

The second possible analysis for depictives is as a simple adjunct. In this analysis, the control relationship between the controller and the depictive is still there, but it is represented by co-indexing, meaning that the depictive is analyzed as a single word that modifies a controller in the main clause (see Williams, 1980; Winkler, 2011).

As for the first analysis, which is the small clause analysis, there is some criticism in the literature against this analysis. For example, Bruening (2018) argues against analyzing depictives as small clauses. He compares depictive constructions with other constructions that should be analyzed as small clauses, suggesting that depictives are different from these constructions. Resultative (19a), caused motion (19b), particle verb (19c) and double object (19d) constructions (all the examples below are quoted from Bruening, 2018, p. 1) are suggested to be small clauses by Kayne (1985), Folli and Harley (2006), Kayne (1985) and Harley (1997), respectively.

(19) a. 'Martha hammered the metal flat'.

b. 'Jerome waltzed Matilda across the room'.

c. 'They sponged the water up'.

d. 'Melinda wrapped her friend a present'.

The main point behind suggesting that depictives are different is that the semantic meanings of these constructions should be reflected by the syntactic analysis. For example, in the resultative construction in (19a), the meaning is that Martha did hammering and the result is that the mental is flat. This example is analyzed in the syntax as follows: the Martha is the subject of the verb hammer. This event caused a result, which is the mental is flat. This result is analyzed in the syntax as a small clause. This means that the mental is not an argument of the first predicate hammer, but it is a part of the result. Bruening (2018) argues that depicitves are different from resultatives and other constructions in this regard. In depictive constructions, the controller is an argument of the main predicate, meaning that analyzing depictives as small clauses is based on wrong semantic analysis, because the controller is a part in the main event and the depictive modifies this controller at the time of event occurrence. Also, there are important syntactic differences between both structures. For example, resultatives can predicate an NP that is not an argument of the main predicate, while the NP in depictive constructions must be an argument of the main predicate, because a depictive modifies a property of a participant that holds through the event (see Rothstein, 2008; Pylkkänen, 2008; Bruening, 2018). However, as mentioned above, MSA is different in this characteristic. This means that a participant can be involved in the event even if it is not an argument. 
The most important point in the previous discussion against analyzing depictives as small clauses is that the controller semantically is a participant in the main event and this makes depictives different from other constructions that are analyzed as small clauses, such as resultatives, where the subject of the result semantically is not involved in the main event. However, it is possible to analyze depictives as small clauses in syntax by suggesting that the depictive clause has a PRO functioning as a subject of the depictive predicate, as mentioned above, but the problem will be in the semantic face of this analysis. Analyzing depictives as small clauses can be represented in LFG by the following f-structure, in which the f-structure in (20b) provides an analysis for the example in (20a):

(20) a. John left angry.

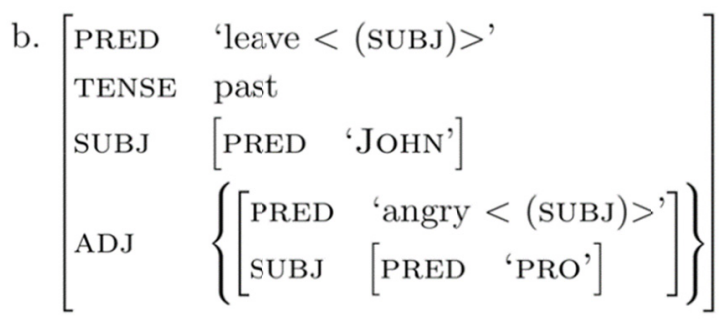

The f-structure in (20b) shows that the main clause in example (20a) contains the verb left, which requires a subject and this requirement is fulfilled by the embedded f-structure that contains the noun John, which functions as the subject of the main clause. The relationship between the main predicate and the depictive is shown in terms of adjunction, meaning that the subordinate clause functions as an adjunct. The relationship between the depictive and the controller is a control relation, where the empty PRO is controlled by the subject of the main predicate John (see Winkler, 2011) for more details about control relation).

However, in this paper, we agree with the point that depictive constructions are different in the semantic level from constructions that should be analyzed as small clauses and this motivates a different analysis. Another argument against the small clause analysis comes from the semantic meaning of depictives as well. As stated above, depictives in MSA and other languages are morphologically adjectives and we suggest that they do the same function that is done by adjectives. The only difference between depictives and normal adjectives is that depictives modify the noun in the time of event only, while adjectives usually do that for long time. We suggest that depictives and adjectives should have the same analysis.

In LFG, modifiers including adjectives are represented at f-structure as members of a set of adjuncts ADJ, because there is no limit to the number of these modifiers that can occur in a phrase. This is an important difference between arguments and adjuncts. If we try to represent the adjectival modifier British in example (21a), it should be a member of the adjunct set named ADJ. This set modifies the noun woman, which can be modified by more than one adjective. The following f-structure shows this analysis:

(21) a. British woman

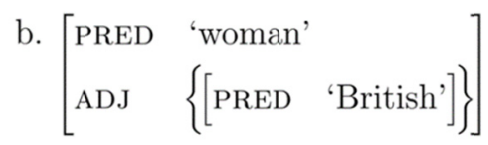

In a phrase that has more than one modifier, each modifier appears in a separate f-structure that appears as a member of the modifying set ADJ. The following f-structure in (22b) represents the example in (22a), which contains two adjectives short and British modifying the noun woman:

(22) a. short British woman

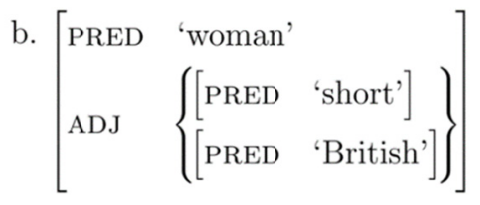


The same analysis is suggested for depictives in this paper, because they have the same function as stated. Depictives are similar to adjectives in that they have the same morphological forms and they do the same syntactic functions. The adjective modifies a noun and depictives do the same thing to a participant in the main predicate. The only difference between them is in the length of the period of modification and this is a semantic issue should be treated in semantic level. In this analysis, the set of ADJ, which represents the depictive, should appear in the f-structure of the controller. For instance, the example in (2a) (repeated in (23a)), should have the analysis in the f-structure in (23b). In this f-structure, the depictive gādib-an 'angry' is represented in a set that is located inside the f-structure of the subject, because the depictive here modifies this subject, which is the controller. Importantly, the f-structure shows the agreement between the controller, which is masculine and singular, and the depictive, which is masculine and singular as well.

$$
\begin{aligned}
& \text { (23) a. ğāâa sālim-un gàădib-an. } \\
& \text { come.PFV.3SGM Salem-NOM angry.APTCP.SGM-ACC } \\
& \text { 'Salem came angry' } \\
& \text { b. }\left[\begin{array}{lll}
\text { PRED } & \text { 'come < (SUBJ)>' } \\
\text { TENSE } & \text { past } \\
\text { SUBJ } & \left.\left[\begin{array}{lll}
\text { PRED } & \text { 'SALEM' } \\
\text { GN } & \text { M } & \\
\text { NUM } & \text { SG } & \\
& \text { ADJ } & \left\{\begin{array}{ll}
\text { PRED } & \text { 'ANGRY' } \\
\text { GN } & \text { M } \\
\text { NUM } & \text { SG }
\end{array}\right]
\end{array}\right]\right\}
\end{array}\right.
\end{aligned}
$$

This analysis can cover more than one depictive too. Like adjectives, depictives can be multi-ple. The following example shows two depictives modifying one participant. The second depictive ba $\bar{k} \bar{l}$-an 'crying' in this example is represented in a separate f-structure inside the set, which is inside the f-structure of the subject.

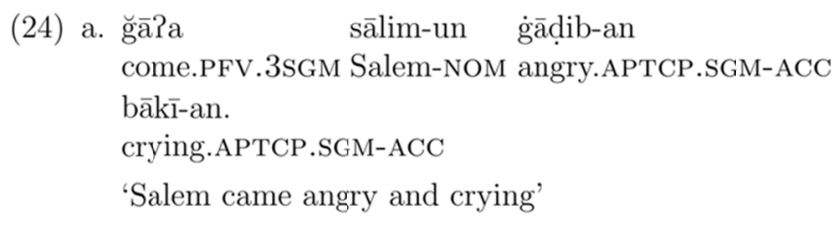

However, examples such as the two examples in (7a) and (7b) above, repeated in (25a) and (25b) below, make a problem for our analysis in this paper. In both examples, depictives require an object that carries an accusative case marking and this indicates that they are predicates. The depictive mumattil-an 'representing' in example (25a) (written in italic font) requires an object function that is filled by mudîr-a 'manager', which is in the accusative case. In the same way, the depictive därib-an 'striking' in example (25b) requires an object, which is proper noun camr-an 'Amr' and it is in the accusative case. 
(25) a. haḍara ḩālid-un mumattill-an

attend.PFV.3sGM Khaled-NOM representing.APTCP.SGM-ACC

mudīr-a al-šarikat-i.

manager-ACC DEF-company-GEN

'Khaled attended representing the manager of the company'

b. gāardara zayd-un dārib-an camr-an.

leave.PFV.3SGm Zayd-NOM striking.APTCP.SGM-ACC Amr-ACC

'Zayd left striking Amr'

This problem could be solved by one of two solutions: the first one is done by arguing that depictives can be analyzed as single modifiers in some constructions and as predicates in others. The second solution is by assuming that the two nouns in accusative case in both examples in (25) are not objects. In the first solution we should add some changing to our analysis and assume that depictives in MSA can be a single modifier as illustrated above and should be analyzed as a single adjunct and they can be predicates requiring some functions and should be analyzed as a clause modifying a participant in the main clause.

Even the depictives in the two examples in (25) under this assumption can be analyzed as a single adjunct, because the two depictives and the following nouns can be linked together to form construct phrases and in this construction, the following nouns will carry a genitive case marking, meaning that they will not be valid to function as an object of the preceding depictives. The following examples illustrate:

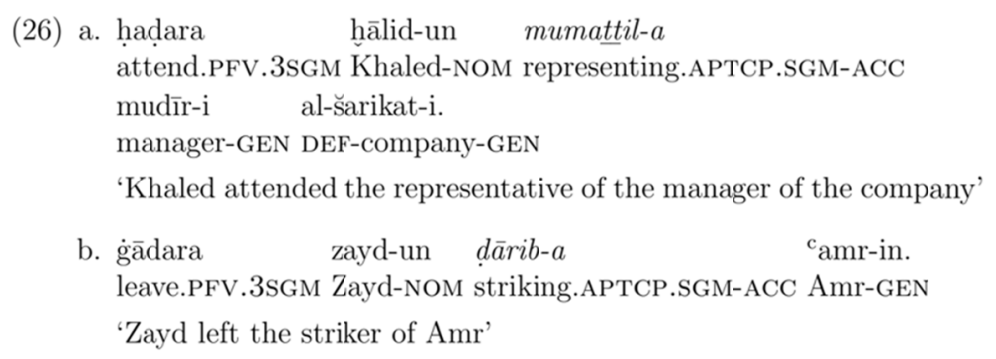

However, the problem with this analysis is that if we analyze a depictive as a predicate, we need a subject, which should be assumed to be a PRO that is controlled by the controller. This will support the small clause analysis for depictives, because if we argue for the existing of PRO, it should be in all constructions of depictives. The following f-structure illustrates this analysis by using the example in (25b), repeated as (27a):

$$
\begin{aligned}
& \text { gāarara zayd-un dārib-an } \quad{ }^{\mathrm{c}} \text { amr-an. } \\
& \text { leave.PFv.3SGm Zayd-NOM striking.APTCP.SGM-ACC Amr-ACC } \\
& \text { 'Zayd left striking Amr' } \\
& \text { b. [PRED 'leave }<\text { (SUBJ) }>\text { ' } \\
& \text { TENSE past } \\
& {\left[\begin{array}{ll}
\text { PRED } & \text { 'ZAYD' } \\
\text { GN } & M
\end{array}\right.}
\end{aligned}
$$

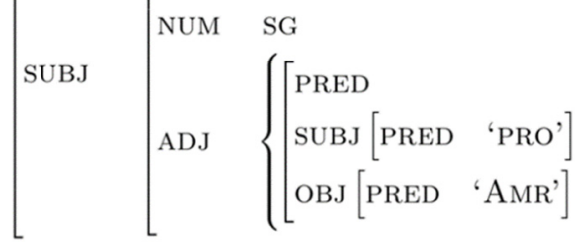

$$
\begin{aligned}
& \text { 'striking }<(\text { SUBJ, OBJ })>\text { '] }]\}]
\end{aligned}
$$

If we compare between the f-structure in (20b), which is supposed to represent the small clause analysis in LFG and the f-structure in (27b), we find that the set of adjunct is inside the f-structure of the subject (27b) and this means that the depictive clause modifies this subject in the same way as an adjective modifies a noun.

This paper supports the second analysis for the two examples in (25), meaning that the two nouns in accusative case that follow both depictives are not objects, but they are the second part of construct phrases. The two examples in (26), in which the same nouns carry a genitive case marking support this analysis. This means that 
we will argue that in MSA the second part of a construct phrase can be separated and carries an accusative case marking and the fact that both constructions deliver the same semantic meaning supports this analysis. In this way, we have the same analysis for single adjectives that function as depictives and have the same view about the participant in the main predicate, which is not controlling any PRO in another clause. Therefore, we can represent an example like (26b), repeated in (28a) in the f-structure in (28b), where the second part from the construct phrase dārib-a $c^{a m r-i n}$ 'the striker of Amr', which is the proper noun Amr is represented as a specifier of the depictive. We claim in this paper that an example, such as (25b), repeated as (29a), which delivers the same semantic meaning should have the same analysis. Therefore, the depictive and its following proper noun, will be analyzed as a construct phrase and the only difference between the two f-structures bellow is the case marking of the proper noun $A m r$, which is a genitive case marking in (28b) and an accusative case marking in (29b).
gàdara
zayd-un dērib-a
camr-in.
leave.PFV.3SGm Zayd-NOM striking.APTCP.SGM-ACC Amr-GEN
'Zayd left striking Amr'

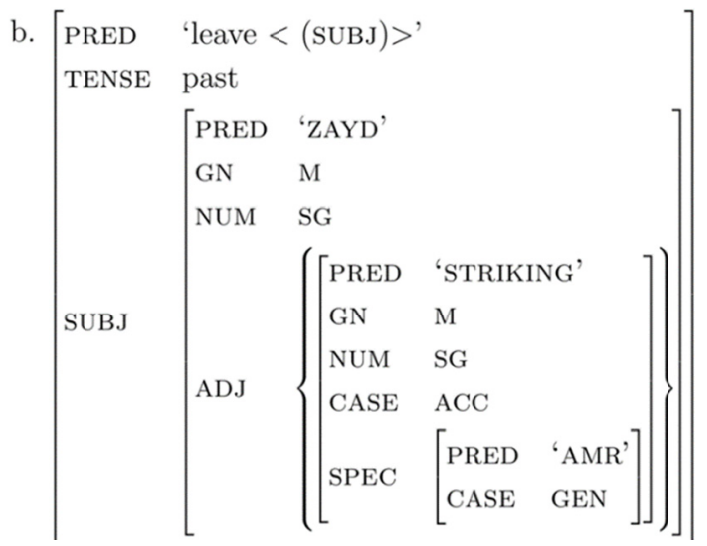

(29) a. gādara zayd-un dārib-an 'amr-an.

leave.PFV.3SGM Zayd-NOM striking.APTCP.SGM-ACC Amr-ACC

'Zayd left striking Amr'

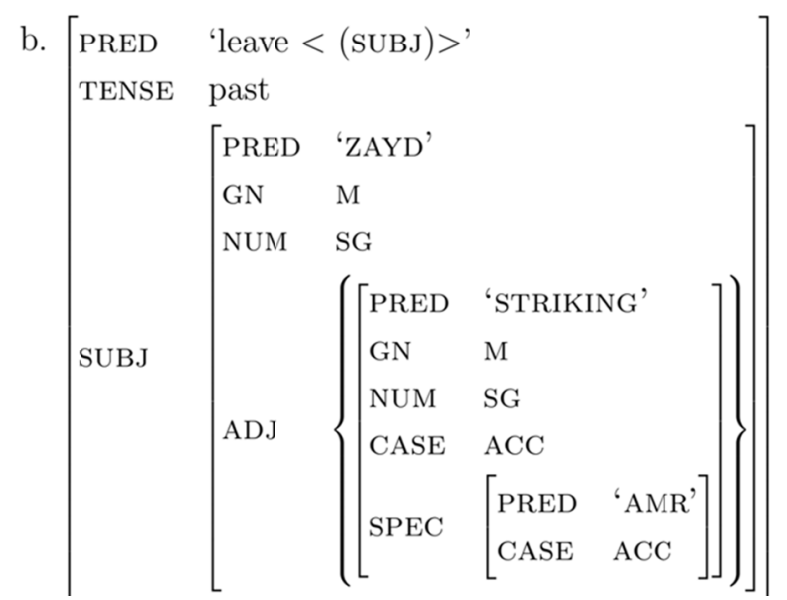

\section{Conclusion}

This paper has dealt with important issues in the semantic and syntactic analysis of depictives in general and in MSA. We have tried to solve a problem in MSA caused by mixing two categories, namely, depictives and adverbs. In this regard, we has analyzed adjectives in accusative case as depictives and verbal nouns in accusative case as adverbs. In the syntax, this paper has discussed two possible analyses in generative syntax, where depictives are analyzed as small clauses or single adjuncts. This issue has been discussed by using a new framework, which is LFG, in analyzing depictives. The conclusion in this paper is that depictives should be analyzed as single adjuncts, but they should be like adjectival constructions in that they modify a head noun in the main predicate. 


\section{References}

Alaqili, A. (n.d.). Sharh ebin agil. alfisaliah.

Andrews, III. A. (1983). A note on the constituent structure of modifiers. Linguistic Inquiry, 14(4), 695-697.

Bartsch, R. (1976). The grammar of adverbials. North-Holland.

Bayer, S. L. (2013). Confessions of a lapsed Neo-Davidsonian: Events and arguments in compo-sitional semantics. Routledge.

Berger, C. B. (2005). Depictive agreement and the development of a depictive marker in swiss ger-man dialects (p. 141). Secondary Predication and Adverbial Modification: The Typology of Depictives.

Bruening, B. (2018). Depictive secondary predicates and small clause approaches to argument structure. Linguistic Inquiry, 49(3), 537-559. https://doi.org/10.1162/ling_a_00281

Chomsky, N. (1981). Lectures on Government and Binding. Dordrecht: Foris Publications.

Chomsky, N. (1986). Barriers. Cambridge, MA: The MIT Press.

Dalrymple, M. (2001). Lexical functional grammar (Vol. 42). New York: Academic Press. https://doi.org/10.1163/9781849500104

Dik, S. C., \& Hengeveld, K. (1991). The hierarchical structure of the clause and the typology of perception-verb complements. Linguistics, 29(2), 231-260. https://doi.org/10.1515/ling.1991.29.2.231

Ernst, T. (2000). Manners and events. Events as Grammatical Objects. Dordrecht: Kluwer.

Folli, R., \& Harley, H. (2006). On the licensing of causatives of directed motion: Waltzing matilda all over. Studia Linguistica, 60(2), 121-155. https://doi.org/10.1111/j.1467-9582.2006.00135.x

Geuder, W. (2002). Oriented adverbs: Issues in the lexical semantics of event adverbs.

Harley, H. (1997). If you have, you can give (pp. 193-207). In Proceedings of the 15th West Coast Conference on Formal Linguistics, CSLI Publications Stanford, CA.

Himmelmann, N. P., \& Schultze-Berndt, E. F. (2005). Secondary predication and adverbial modifica-tion: the typology of depictives. Oxford University Press on Demand. https://doi.org/10.1093/acprof:oso/9780199272266.001.0001

Himmelmann, N. P., \& Schultze-Berndt, E. F. (2006). Issues in the syntax and semantics of participant-oriented adjuncts (pp. 1-68). Secondary predication and adverbial modification: The typology of depictives.

Hoekstra, T. (1988). Small clause results. Lingua, 74(2-3), 101-139.

Jackendoff, R. S. (1972). Semantic interpretation in generative grammar. https://doi.org/10.1016/0024-3841(88)90056-3

Jackendoff, R. S. (1977). X-Syntax: A Study of Phrase Structure. Cambridge, MA: MIT Press.

Kayne, R. (1985). Principles of particle constructions. In G. Jacqueline, O. HansGeorg \& P. JeanYves (Eds.), Grammatical representation. Foris Publishers.

Laughren, M. (1992). Secondary predication as a diagnostic of underlying structure in pama- nyungan languages. Thematic structure: Its role in grammar, 16, 199.

McConnell-Ginet, S. (1982). Adverbs and logical form: A linguistically realistic theory. Language, 144-184. https://doi.org/10.2307/413534

McGregor, W. (2005). Quantifying depictive secondary predicates in australian languages (pp. 173-200). Sec-ondary Predication and Adverbial Modification: The Typology of Depictives. https://doi.org/10.1093/acprof:oso/9780199272266.003.0005

McNulty, E. M. (1988). The syntax of adjunct predicates. Ph. D. thesis, University of Connecticut.

Müller-Bardey, T. (1989). Koprädikation als grundlegende syntaktische operation. In Interna-tionales interdisziplinäres Kolloquium Sprache und Denken: Variation und Invarianz in Lin-guistik und Nachbardisziplinen. Lenzburg/Schweiz, 16, 19.

Müller-Bardey, T. (2005). Adverbials and depictives as restrictors (pp. 107-140). Secondary Predication and Adverbial Modification: The Typology of Depictives. https://doi.org/10.1093/acprof:oso/9780199272266.003.0003 
Müller, S. (2000). Zustandspra“dikate im deutschen. Ruhr-Universität Bochum, 23.

Müller, S. (2002). Complex predicates: Verbal complexes, resultative constructions, and particle verbs in German (Vol. 13). CSLI publications Stanford.

Nichols, J. (1978). Secondary predicates (Vol. 4, pp. 114-127). Annual Meeting of the Berkeley Linguistics Society. https://doi.org/10.3765/bls.v4i0.2216

Platt, J. T., \& Platt, H. K. (1972). Orientation of manner adverbials. Research on Language \& Social Interaction, 5(2), 227-249. https://doi.org/10.1080/08351817209370298

Pylkkänen, L. (2008). Introducing arguments (Vol. 49). MIT press. https://doi.org/10.7551/mitpress/9780262162548.001.0001

Rothstein, S. (2008). Structuring events: A study in the semantics of lexical aspect (Vol. 5). John Wiley \& Sons.

Rothstein, S. D. (1983). The syntactic forms of predication. Ph. D. thesis, Massachusetts Institute of Technology.

Ryding, K. (2005). A reference grammar of modern standard Arabic. Cambridge University Press. https://doi.org/10.1017/CBO9780511486975

Schultze-Berndt, E., \& Himmelmann, N. P. (2004). Depictive secondary predicates in crosslin-guistic perspective. Linguistic Typology, 8(1), 59-131. https://doi.org/10.1515/lity.2004.004

Simpson, J. (2005). Depictives in english and warlpiri. Secondary Predication and Adverbial Modification. The Typology of Depictives, 69-106. https://doi.org/10.1093/acprof:oso/9780199272266.003.0002

Stowell, T. (1982). Subjects across categories. Linguistic Review, 2(3), 285-312.

Van der Auwera, J., \& Malchukov, A. (2005). A semantic map for depictive adjectivals (pp. 393-421). In Secondary predication and adverbial modification: the typology of depictives. Oxford.https://doi.org/10.1093/acprof:oso/9780199272266.003.0013

Williams, E. (1980). Predication. Linguistic Inquiry, 11(1), 203-238.

Winkler, S. (2011). Focus and secondary predication (Vol. 43). Walter de Gruyter.

\section{Copyrights}

Copyright for this article is retained by the author, with first publication rights granted to the journal.

This is an open-access article distributed under the terms and conditions of the Creative Commons Attribution license (http://creativecommons.org/licenses/by/4.0/). 